\title{
Tolerability and hydrating effects of an anti-aging gynaecological collagen cream in women in menopause
}

\author{
Andrea F. D. Di Stefano', Milko M. Radicioni' ${ }^{1}$, Andrea Vele ${ }^{1}$, Anna Mancarella Eberhardt', \\ Giorgio Caccia $^{3}$, Francesca Focanti ${ }^{4}$, Enrica Salvatori ${ }^{4}$ \\ ${ }^{1}$ CROSS Research S.A., Arzo, Switzerland \\ ${ }^{2}$ Chiasso, Switzerland \\ ${ }^{3}$ Service for Gynaecology and Obstetrics, Ospedale Regionale di Mendrisio, Mendrisio, Switzerland \\ ${ }^{4}$ Aziende Chimiche Riunite Angelini Francesco (ACRAF) S.p.A., Santa Palomba, Rome, Italy \\ Email: andrea.distefano@croalliance.com
}

Received 13 December 2013; revised 12 January 2014; accepted 20 January 2014

Copyright (C) 2014 Andrea F. D. Di Stefano et al. This is an open access article distributed under the Creative Commons Attribution License, which permits unrestricted use, distribution, and reproduction in any medium, provided the original work is properly cited. In accordance of the Creative Commons Attribution License all Copyrights (C) 2014 are reserved for SCIRP and the owner of the intellectual property Andrea F. D. Di Stefano et al. All Copyright (C) 2014 are guarded by law and by SCIRP as a guardian.

\section{ABSTRACT}

Background and Aims: A gynaecological cream containing collagen, phytocollagen, hyaluronate and vitamins was investigated in women in menopause. Methods: The cream was daily applied to the vaginal mucosa and the perineal skin as well as to the abdominal skin (healthy skin used as control) for 1 week and then on alternate days for other 2 weeks. Skin hydration and viscoelasticity were measured at baseline and after 8 and 21 days by Corneometer ${ }^{\circledR}$ CM 825 and Cutometer ${ }^{\circledR}$ MPA 850, respectively. The product use comfort and the moisturising of the vaginal mucosa were evaluated by the volunteers through a questionnaire and a visual analogue scale, respectively. Results: The local tolerability was excellent for nearly all of the volunteers $(90 \%-95 \%)$ and according both to dermatologist's and gynaecologist's evaluation. Related adverse reactions had a frequency of $15 \%(10 \%$ vulvovaginal burning sensation and $5 \%$ vulvovaginal discomfort). The topical hydration increased both in the perineal and the abdominal skin. Hydration increase vs. baseline was more marked on day 8 than on day 21 and was significant in the abdominal skin (p-value $<0.0001$ ). The vaginal moisturising improved significantly (p-value $<0.0001$ ) both on day 8 and 21 vs. baseline. Small changes in the viscoelasticity parameters were observed in both the perineal and the abdominal skin. Few significant improvements were $R 1$ and $R 8$ decreases in the perineum and $\mathrm{RO}$ increase in the abdomen. Conclusions: The tested cream represents a safe product with proven moisturising effect towards the vaginal mucosa when daily applied by menopausal women.

\section{KEYWORDS}

Skin Hydration; Vaginal Moisturiser; Skin Viscoelasticity; Corneometer; Cutometer; Perineum

\section{INTRODUCTION}

Perimenopause and menopause are conditions characterised by several changes that affect the structural integrity of vagina and vulva and that involve also the urinary tract [1-3]. In fact, oestrogen maintains the thickness of the vaginal epithelium and promotes the synthesis of collagen and elastin in the vaginal connective tissue. Collagen is the major macromolecular component of derma, which ensures the tissue elasticity, pliability, thickness and tone. The collagen of types I and III decreases in derma by $30 \%$ in the first 5 years following menopause [4-7]. The thinning of the vaginal epithelium, the hyalinisation of collagen and the elastin fragmentation lead to hypotonus, relaxation, dryness deriving from a deficiency in connective supports.

A sedentary lifestyle, lack of exercise, childbirth, or other events may also cause relaxation of the perineal muscles and of the tissues and muscles that surround the genital area and regulate the urinary functions. This condition may cause very frequent disturbances: from small urine leaks when coughing or laughing or dyspareunia or constipation up to severer disorders such as enuresis, recurrent cystitis and prolapse.

The use of moisturisers is a primary option in the treatment and prevention of vaginal symptoms, as showed in several published trials [3].

The principal components of moisturising products 
improve the skin hydration either by an occlusive or by a humectant mechanism. Fundamentally, the ability of moisturisers to restrain the transepidermal water loss and to increase the water content in the stratum corneum is an essential, though not unique, property required to improve also the skin mechanics [8-12]. However, many other components exert a synergistic beneficial effect on the epidermis through various mechanisms [12]. Polypeptides, frequently included in moisturising preparations, are able to stimulate enzymatic processes, e.g. the collagen neosynthesis, and to enhance the dermal metabolism $[13,14]$. The percutaneous absorption of hyaluronic acid was proven when applied with topical preparation to the intact skin though the strongly hydrophilic nature of the compound [15]. Vitamins A, C, E and B3 contribute to the anti-aging effect of many topical products. All the 4 vitamins may have an antioxidant effect on the stratum corneum [12,16-22]. Furthermore, both vitamin A in the precursor form of retinol and in the activated form of retinoic acid and vitamins C and B3 can promote the neosynthesis of collagen in the dermis [16,19,22-27]. Very frequently used components are also antioxidants of botanical origin. In particular, polyphenols and soy isoflavones exert a proven anti-aging effect through antioxidant mechanisms.

In the present study, a marketed cream-class II A medical device-containing collagen, hyaluronate, vitamins A, C, E and B3 and isoflavones was investigated in menopausal women who applied it for a period of 3 weeks.

\section{METHODS}

This mono-centric study comprised 20 women in good health and in menopausal status (natural or surgical) for at least one year. The volunteers were included in the study at the Phase I Unit of CROSS Research S.A., Arzo, Switzerland, from 16NOV11 and 15DEC11.

The volunteers selected for the study presented a reduced elasticity of the perineal skin and vaginal dryness reported by the screened women without any instrumental ascertainment. Before definitive enrolment in the study, an evaluation of the vulvar and vaginal mucosa was done by a gynaecologist and an evaluation of the perineal and abdominal skin was performed by a dermatologist. The gynaecological and dermatological examinations prevented the inclusion of women with relevant skin or mucosal alterations.

Other exclusion criteria were 1) intake of any medication judged by the investigator as incompatible with the study and in particular any substitutive hormonal therapy 2), known sensitivity to skin care products or cosmetic products, 3) clinically relevant abnormal physical findings, 4) history of bacterial infection at the urinary tract in the previous 2 weeks and 5) unwillingness to provide written informed consent.

Primary objective of the study was the investigation of the local tolerability of the test product (Perilei ${ }^{\mathrm{TM}}$ Pausa) applied according to a multiple dose regimen. The study was also aiming at investigating the hydration and elasticity of the perineal and abdominal skin and the moisturising of the vaginal mucosa during and after multiple dose application of the product.

Since no previous clinical investigation of the test product was performed, the sample size determination was not based on a statistical evaluation. A total of 20 subjects were considered adequate to achieve the objectives of the trial.

Measurements of skin hydration and elasticity were performed using a specific multi-probe device in accordance with the instrument producer instructions [28].

The measurement of skin elasticity (done with Cutometer MPA 580) is based upon peculiar mechanical properties of human skin and represents a non-invasive method whose use has become solid and widely spread in dermatology and cosmetics [29-35] and acknowledged by the European Expert Group on Efficacy Measurement of Cosmetics and other Topical Products (EEMCO) [36].

The corneometer CM 825 allows the measurement of stratum corneum hydration. It is regarded as a reliable measure of skin conditions and also this method gained validity and use diffusion in dermatology and cosmetics [37-39]. The reliability and the reproducibility of these measures were previously demonstrated [40-42].

The volunteers evaluated the moisturising effect on the vaginal mucosa using a Visual Analogue Scale (VAS) 0 $100 \mathrm{~mm}$. The volunteers were asked a list of questions in order to evaluate the comfort of the cream use.

The cream was daily applied for 1 week in the evening. During the following 2 weeks, it was applied on alternate days in the evening, i.e. on days $8,10,12,14,16,18$ and 20.

The study participants applied the product in the evening before going to bed on the days scheduled for applications. At each application, 1 tube $(5 \mathrm{~mL})$ was used for the perineal skin and vaginal mucosa and 1 tube (5 $\mathrm{mL}$ ) was used for the abdominal skin. During each application to the vaginal mucosa, the subjects were lying in the supine position. The applicator was slowly introduced into the vagina and about the half of the first tube was extruded. The remaining amount of cream was applied to the perineal and vulvar area (see Figure 1). The subject rubbed gently the cream with circular movements without rinsing. The subjects gently spread the cream with circular movements, when they applied it to the abdominal skin.

The time points for the assessments of vaginal and skin moisturising and skin elasticity were scheduled at 


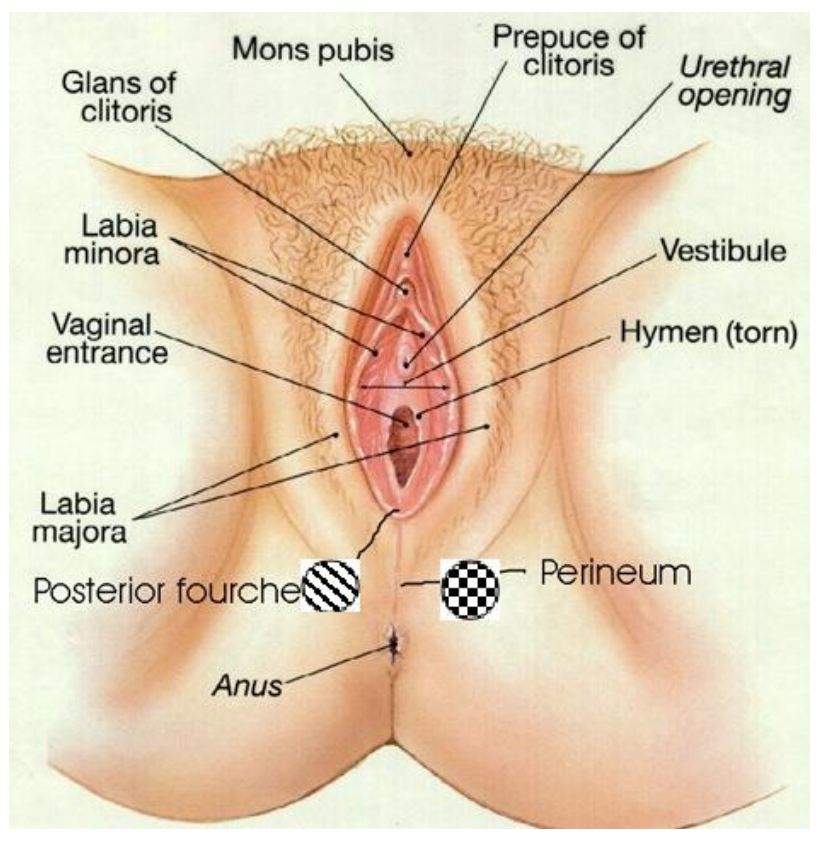

Figure 1. The diagonal bar zone indicates the site for the measurement of the skin moisturising. The dazed square zone indicates the site for the elasticity measurements.

the end of the daily application period on day 8 and then at the end of the study, on day 21.

Application site and expected effects on moisturising and elasticity were circumscribed to skin or vaginal mucosa. For this reason, the safety and tolerability assessments were limited to the spontaneous reporting of adverse reactions and to the subjective and objective assessment of local tolerability.

The study documentation was reviewed by the independent ethics committee of Canton Ticino and was conducted in compliance with the Swiss rule "Federal Law on Medicinal Products and Medicinal Devices (Law on Therapeutic Products LATer)” and in accordance with the Declaration of Helsinki and the general principles of ICH Harmonised Tripartite Guidelines for GCP. The study participants did not undergo any study procedure before signing the written informed consent form.

\subsection{Study Parameters and Data Analysis}

\subsubsection{Skin Moisturising Measurement}

The moisture retention capacity of the skin relates to the hydric dielectric constant [43] and can be measured in the stratum corneum at a depth of $10-20 \mu \mathrm{m}$. This ensures that the measurement is not influenced by capillary blood vessels. An increase in capacitance means an increase in skin hydratation.

Triplicate skin hydration measurements were performed at baseline (day 1) and post-dose on days 8 and 21 both in the abdominal right upper quadrant and in the perineal zone. The zone of application of the Corneometer ${ }^{\circledR} \mathrm{CM}$
825 probe was near the centre of the perineum, below the vagina (see Figure 1, diagonal bar zone). The same zone was kept for all the measurements. The instrument software calculated the mean capacitance value of each triplicate measurement.

\subsubsection{Skin Elasticity Measurement Using the Cutometer ${ }^{\circledR}$ MPA 580 Probe}

Single elasticity measurements were performed at baseline (day 1) and on days 8 and 21 both in the abdominal right upper quadrant and in the perineal zone in an area different from that chosen for the moisturising measurement (see Figure 1, dazed square zone). The same zone was kept for all the measurements. The Cutometer ${ }^{\circledR}$ built-in probe applied to the skin surface originates a vacuum (a negative pressure of 450 mbar was applied) that sucks the skin into the probe. After $2 \mathrm{~s}$ of suction, the negative pressure is instantaneously interrupted thus allowing the skin moving back out of the probe and relaxing for $2 \mathrm{~s}$. The movements of the skin inside the probe (elongation and retraction) are measured by a glass prism according to the principle of light ray interruption.

The cutometer generates an elongation and a retraction curve depicting each immediate skin deformation (see Figure 2). The amplitudes (from R0 to R8) and the areas (F0 and F1) measured by the instrument, while constructing the curves, are indices which allow the interpretation of the viscoelastic properties of the skin. The parameters obtained through the viscoelasticity measurements are listed in Table 1.

Mode 1 was applied to all study measurements. Each measurement had a duration of at least $4 \mathrm{~s}$, including $2 \mathrm{~s}$ of suction and $2 \mathrm{~s}$ of relaxation.

\subsection{Statistical Analysis}

The values measured on days 8 and 21 were compared vs. day 1 by a paired t-test (or by a Wilcoxon signed-rank test in case of lack of normality) with a 0.05 two-sided significance level.

VAS values were described using classic descriptive statistics and were compared vs. baseline (day 1) using a paired t-test (or by a Wilcoxon signed-rank test in case of lack of normality) with a 0.05 two-sided significance level.

Questionnaire items were summarised by presenting tables.

\subsection{Safety Variables}

Safety variables included the local tolerability on the abdominal and perineal skin and vaginal mucosa evaluated by the dermatologist, the gynaecologist and the study participants, the recording of adverse events (AEs) 


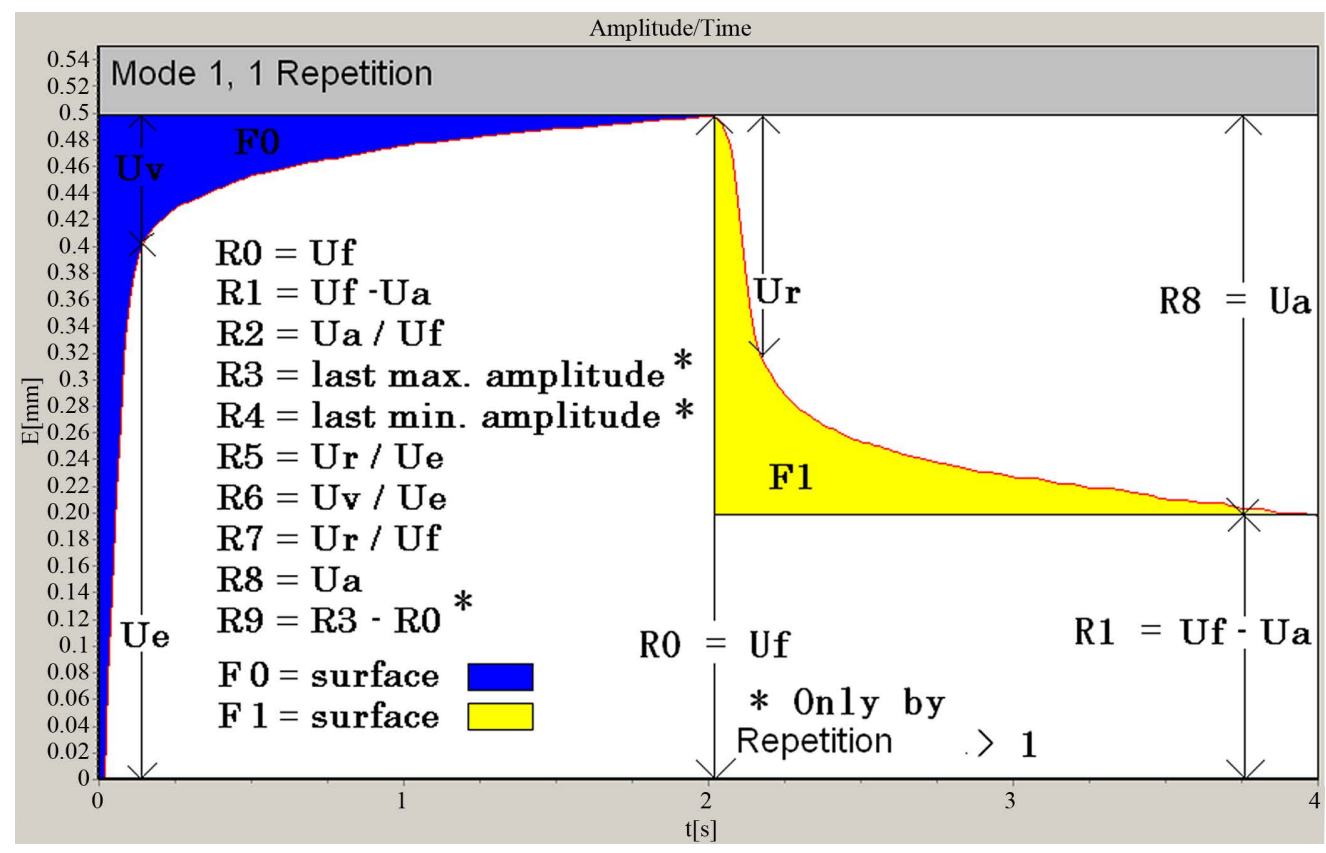

Figure 2. Example of a skin elongation curve obtained after 1 cycle of skin suction-relaxation done in mode 1 using a Cutometer ${ }^{\circledR}$ MPA 580 probe.

Table 1. Linear and superficial parameters derived from the skin deformation curve by measuring the skin viscoelasticity.

\begin{tabular}{|c|c|c|}
\hline Index & Expression & Point of measurement \\
\hline Ro & Uf & $\begin{array}{l}\text { Length of the skin when elongated (in mm) } \\
\text { (= highest point of the first curve) }\end{array}$ \\
\hline $\mathbf{R} 1$ & Uf-Ua & $\begin{array}{l}\text { Length of the skin after elongation and retraction (in mm) } \\
\text { (= lowest point of the first curve). }\end{array}$ \\
\hline $\mathbf{R} 2$ & Ua/Uf & $\begin{array}{l}\text { Extent of recovery of the skin length } \\
\text { (= ability of the skin to return to its initial position after deformation, e.g. the closer the value is to } 1(100 \%) \text { the more } \\
\text { elastic the skin is). }\end{array}$ \\
\hline R5 & Ur/Ue & $\begin{array}{l}\text { Net elasticity. } \\
\text { (The closer the value is to } 1(100 \%) \text { the more elastic the skin is). }\end{array}$ \\
\hline R6 & Uv/Ue & $\begin{array}{l}\text { Ratio of viscosity and elasticity part of the skin when elongated } \\
\text { (= portion of the viscoelasticity on the elastic part of the curve. The smaller the value the higher the elasticity). }\end{array}$ \\
\hline R7 & Ur/Uf & $\begin{array}{l}\text { Speed of recovery of the skin length } \\
\text { (The closer the value is to } 1(100 \%) \text { the more elastic the skin is). }\end{array}$ \\
\hline R8 & Ua & $\begin{array}{l}\text { Length of skin retraction after elongation (in mm) } \\
\text { (The closer Ua and Uf, the greater the ability of the skin to return to its original state). }\end{array}$ \\
\hline F0 & Uf $\mathrm{x}$ suction time & $\begin{array}{l}\text { Skin distortion during elongation } \\
\text { This area is deducted from the total area (rectangle maximal amplitude and time). A completely elastic material will } \\
\text { show no area at all, the closer the value to } 0 \text { the more elastic the material. }\end{array}$ \\
\hline F1 & Uf x relaxation time & $\begin{array}{l}\text { Skin distortion during retraction } \\
\text { This area is deducted from the total area (rectangle maximal amplitude and time). A completely elastic material will } \\
\text { show the complete area (total area and F1 are the same), the closer the value for total area minus F1 to } 0 \text { the more elas- } \\
\text { tic the material. }\end{array}$ \\
\hline
\end{tabular}

and the physical examination.

Both the dermatologist and the volunteers scored the product local tolerability at the application sites of abdominal and perineal skin on days 8 and 21. The local tolerability of the product at the application site of the vaginal mucosa was also scored by both the gynaecologist and the volunteers. For all the evaluations, the following 5-point scale was used:

1 = excellent (no skin reaction);

$2=\operatorname{good}$ (small skin reaction that spontaneously re- 
solves);

$3=$ moderate (skin reaction tolerated with difficulty by the subject);

$4=$ poor (skin reaction needing interruption of treatment);

5 = bad (serious skin reaction).

The subjective evaluation was done as response to the dermatologist's or gynaecologist's question: "How do you judge the skin tolerability of the product?”.

\section{RESULTS}

\subsection{Analysis of Moisturising of the Vaginal Mucosa Evaluated by Subjects}

Mean VAS values given by the study participants to evaluate the moisturising of the vaginal mucosa on days 1,8 and 21 and their change from baseline are summarised in Table 2.

Study subjects generally perceived an increase in moisturising of the vaginal mucosa from day 1 to 8 . The VAS value increased more than twice as much as the baseline on average. From day 8 to 21, the moisturising of the vaginal mucosa increased less markedly. The change from baseline was statistically significant at both day 8 and day 21.

\subsection{Evaluation of Skin Moisturising: Capacitance}

For each triplicate measure of capacitance, one mean value calculated by the instrument software was recorded. Capacitance values and their change from baseline are summarised in Table 3. In comparison with baseline, the increment of capacitance was statistically significant both on day 8 and on day 21 only in the abdominal area (p-values $<0.0001$ and 0.0119 ).

The increment observed in the perineal area was not statistically significant.

\subsection{Skin Elasticity Measurement}

Mean elasticity measures taken at the perineal and abdominal application sites with statistically significant changes from baseline are summarised in Table 4 for baseline, day 8 and 21 respectively.

An improvement in the elastic properties of skin was denoted by few significant changes. In detail, R1 de-

Table 2. Mean \pm SD of visual analogue scale (VAS) value (mm) for vaginal mucosa moisturising on days 1 , 8 and 21 , the change from day 1 to day 8 and day 21 with the corresponding statistical test outcomes.

\begin{tabular}{ccccc}
\hline Day 1 & Day 8 & Day 21 & Change to day 8 & Change to day 21 \\
\hline $21.30 \pm 8.60$ & $50.50 \pm 12.71$ & $69.75 \pm 9.03$ & $29.20^{*} \pm 15.75$ & $48.45^{*} \pm 13.37$ \\
\hline p - ra
\end{tabular}

Table 3. Mean \pm SD capacitance for abdominal and perineal skin moisturising on days 1,8 and 21, the change from day 1 to day 8 and day 21 with the corresponding statistical test outcomes.

\begin{tabular}{ccc}
\hline Time & Abdominal skin & Perineal skin \\
\hline Day 1 & $25.55 \pm 8.92$ & $36.76 \pm 11.03$ \\
Day 8 & $35.72 \pm 13.34$ & $40.04 \pm 13.33$ \\
Day 21 & $30.55 \pm 11.90$ & $38.76 \pm 11.63$ \\
Change to day 8 & $10.16^{*} \pm 8.69$ & $3.28 \pm 16.96$ \\
Change to day 21 & $5.00^{*} \pm 8.04$ & $2.00 \pm 15.80$ \\
\hline
\end{tabular}

${ }^{*}$ p-value $<0.05$.

Table 4. Mean \pm SD measures of skin elasticity taken on the perineal and abdominal skin on days 1, 8 and 21, the change from day 1 to day 8 and day 21 with the corresponding statistical test outcomes.

\begin{tabular}{|c|c|c|c|c|c|c|}
\hline & & Day 1 & Day 8 & Day 21 & Change to day 8 & Change to day 21 \\
\hline \multirow{3}{*}{ Perineal skin } & $\begin{array}{l}\mathrm{R0} \\
(\mathbf{m m})\end{array}$ & $0.555 \pm 0.069$ & $0.506 \pm 0.084$ & $0.513 \pm 0.082$ & $-0.049^{*} \pm 0.098$ & $-0.042 \pm 0.099$ \\
\hline & $\begin{array}{c}\mathrm{R} 1 \\
(\mathbf{m m})\end{array}$ & $0.149 \pm 0.172$ & $0.097 \pm 0.039$ & $0.109 \pm 0.045$ & $-0.052^{*} \pm 0.177$ & $-0.041 \pm 0.176$ \\
\hline & $\begin{array}{c}\mathrm{R8} \\
(\mathrm{mm})\end{array}$ & $0.445 \pm 0.060$ & $0.409 \pm 0.075$ & $0.404 \pm 0.066$ & $-0.036 \pm 0.088$ & $-0.041^{*} \pm 0.082$ \\
\hline \multirow{3}{*}{ Abdominal skin } & $\begin{array}{c}\mathrm{Ro} \\
(\mathbf{m m})\end{array}$ & $0.454 \pm 0.051$ & $0.486 \pm 0.067$ & $0.494 \pm 0.072$ & $0.032^{*} \pm 0.059$ & $0.041^{*} \pm 0.060$ \\
\hline & $\begin{array}{c}\mathrm{R8} \\
(\mathrm{mm})\end{array}$ & $0.368 \pm 0.044$ & $0.394 \pm 0.056$ & $0.405 \pm 0.057$ & $0.026 \pm 0.061$ & $0.037^{*} \pm 0.052$ \\
\hline & Fo & $0.071 \pm 0.011$ & $0.117 \pm 0.170$ & $0.073 \pm 0.013$ & $0.046^{*} \pm 0.172$ & $0.002 \pm 0.014$ \\
\hline
\end{tabular}

${ }^{*}$ p-value $<0.05$. 
creased significantly from day 1 to day 8 and R8 decreased significantly from day 1 to day 21 in the perineal region. Indeed, both parameters are inversely proportional to skin elasticity and their decrement denotes an improvement in skin elasticity. With respect to the abdominal region, a significant increase in R0 also denoted some improvement in skin elasticity. The parameter continued to increase slightly from day 1 to 8 and then to 21 .

\subsection{Analysis of Use Comfort}

The product comfort was evaluated positively by the totality of the subjects with respect to most of the asked questions. In detail, all the subjects could easily spread the cream without flowing or greasing or sticking or maculating. With respect to the smell, the $80 \%$ of subjects did not perceive any smell, while the $20 \%$ perceived a pleasant smell.

The $45 \%$ of subjects perceived that the vaginal hydration feeling lasted enough time, while the $55 \%$ found that the hydration feeling lasted for too long time.

\subsection{Adverse Events}

Generally, the treatment was well tolerated by the subjects. The occurrence of side effects was low. In fact, reproductive system disorders affected 3/20 subjects (15\%) with occurrences of vulvovaginal burning sensation and of vulvovaginal discomfort. No other side effects judged as related to the application of the investigational cream occurred.

\subsection{Local Tolerability}

Local tolerability evaluated by the dermatologist at the perineal and abdominal skin, by the gynaecologist at the vaginal mucosa and by the volunteers themselves for all 3 regions is presented in Table 5 .

Local tolerability of the cream was excellent at both assessment time points according to both dermatologist's and gynaecologist's evaluation. The $95 \%$ of the women rated the local tolerability as excellent. The volunteers, who rated the local tolerability of the product as good (10\% on day 8 and $5 \%$ on day 21), experienced some adverse reactions at the reproductive system. The woman, who evaluated the local tolerability of the test product as good on days 8 and 21, experienced a vulvovaginal burning sensation starting from the $9^{\text {th }}$ application up to the last application. Another woman, who evaluated the local tolerability of the test product as good on day 8, had experienced a vulvovaginal burning sensation on the first 3 days of application. After the $3^{\text {rd }}$ application the adverse reaction resolved spontaneously.

\section{DISCUSSION}

The present study demonstrated the safety and the tolerability of a marketed gynaecological cream. The potential effects of the cream on vaginal mucosa and perineal and abdominal skin moisturising and viscoelasticity were also investigated. The study results showed a significant improvement in the moisturising of the vaginal mucosa and the perineal and abdominal skin.

The improvement in the conditions of the application areas was apparent from the objective epidermic hydration measurements on one hand and from the subjective judgement on the other. The topical hydration increased with the daily applications of the cream both at the perineal and the abdominal application sites, as shown by the slight increase in the values of capacitance in the stratum corneum. The change vs. baseline was more marked after 8 days than after 21 days. The improvement in skin moisturising was statistically significant at the abdominal skin application site. The results of the present study are consistent with the literature data [37-40, 44-48]. In particular, the results are consistent with those of $\mathrm{Li}$ et al. [44], who also showed that the measures taken one hour of the application are predictive of the stratum corneum moisturising obtained after a multiple applications for one or 2 weeks. Similarly, Wanitphakdeedecha et al. [48] showed, consistently with the results of the present study, that a cream containing $0.1 \% \mathrm{mu}-$ copolysaccharide polysulphate improves the hydration of the face skin after multiple applications for 28 days and of the skin of the volar side of the forearm after one application.

On average, an improvement in the moisturising of the vaginal mucosa was observed according to the volunteers' evaluation from day 1 to 21 in the present study. In particular, the volunteers judged that the moisturising of the vaginal mucosa increased more than twice as much as the baseline with daily applications of the cream for the initial 8 days. Afterwards, the moisturising continued to increase up to day 21, though less markedly. The improvement in vaginal moisturising evaluated through a VAS was statistically significant (p-value $<0.0001)$ both on day 8 and 21 as compared with baseline.

Results obtained for perineal and abdominal skin viscoelasticity were consistent with previously published data of other similar studies [29,45-48]. In the present study, small changes in the skin elasticity parameters were observed in both perineal and abdominal skin, but their majority did not have statistical significance. A small significant improvement in the elastic properties was observed for the perineal region (R1 and R8 decrease) and secondarily also for the abdominal region (R0 increase). Interestingly, the mean values of R6 and R7 found by Elsner et al. [29] for the vulvar and forearm skin in untreated pre and post-menopausal women are consistent 
Table 5. Local tolerability of the cream applied to the perineal and abdominal skin and to the vaginal mucosa according to the objective evaluation of the dermatologist and the gynaecologist and the subjective evaluation of the volunteers. Number and percentage of subjects are presented $[\mathrm{N}(\mathrm{n} \%)]$.

\begin{tabular}{ccccccccc}
\hline & \multicolumn{3}{c}{ Day 8 } & & & \multicolumn{3}{c}{ Day 21 } \\
\hline & Volunteer & & Dermatologist & Gynaecologist & Volunteer & & Dermatologist & Gynaecologist \\
\hline & Excellent & Good & Excellent & Excellent & Excellent & Good & Excellent & Excellent \\
\hline Perineal skin & $19(95.0)$ & $1(5.0)$ & $20(100)$ & - & $19(95.0)$ & $1(5.0)$ & $20(100)$ & - \\
Abdominal skin & $19(95.0)$ & $1(5.0)$ & $20(100)$ & - & $19(95.0)$ & $1(5.0)$ & $20(100)$ & - \\
Vaginal mucosa & $18(90.0)$ & $2(10.0)$ & - & $20(100)$ & $19(95.0)$ & $1(5.0)$ & - & $20(100)$ \\
\hline
\end{tabular}

with the results obtained in the present study for the perineal and abdominal skin, respectively. Generally, the use of the cream was judged comfortable by the majority of the volunteers with respect to the majority of the questions concerning the use comfort. Vaginal, perineal and abdominal tolerability of the cream was excellent at both assessment time points according to both dermatologist's and gynaecologist's evaluation. Vaginal, perineal and abdominal tolerability was excellent also for almost all the volunteers (90\% - 95\%). Only 3 of them experienced vulvovaginal burning sensation and vulvovaginal discomfort. Among the reported adverse events, only 10 episodes were judged as related to the cream use at a frequency of $15 \%$. In conclusion, the tested cream represents a safe product with proven moisturising effect towards the vaginal mucosa and the perineal skin when applied daily by menopausal women.

\section{ACKNOWLEDGEMENTS}

A.C.R.A.F. S.p.A., Italy, gave the financial support to the project. The relationships between the Sponsor, A.C.R.A.F. S.p.A. and CROSS Research S.A., the dermatologist and the gynaecologist were regulated by financial agreements.

The Sponsor reviewed and approved the study design, was informed about the collection of data and reviewed and approved the analysis and the interpretation of data. The Sponsor also reviewed and approved the manuscript for publication.

MMR, AME and GC reviewed and approved the design of the study, were responsible for the clinical activities and collected the data, AV performed the statistical analysis, FF and ES proposed the study design and reviewed the draft manuscript, AFDD wrote the clinical study report and drafted the manuscript.

All authors read and approved the manuscript.

\section{REFERENCES}

[1] Archer, D.F. (2010) Efficacy and tolerability of local estrogen therapy for urogenital atrophy. Menopause, 17, 194-203. http://dx.doi.org/10.1097/gme.0b013e3181a95581

[2] Bachmann, G.A. and Nevadunsky, N.S. (2000) Diagnosis and treatment of atrophic vaginitis. American Academy of Family Physicians, 61, 3090-3096.
[3] Sturdee, D.W. and Panay, N. (2010) International menopause society writing group. Recommendations for the management of postmenopausal vaginal atrophy. Climacteric, 13, 509-522. http://dx.doi.org/10.3109/13697137.2010.522875

[4] Brincat, M., Moniz, C.J., Studd, J.W., Darby, A., Magos, A., Emburey, G. and Versi, E. (1985) Long-term effects of the menopause and sex hormones on skin thickness. British Journal of Obstetrics and Gynaecology, 92, 256259.

http://dx.doi.org/10.1111/j.1471-0528.1985.tb01091.x

[5] Affinito, P., Palomba, S., Sorrentino, C., Di Carlo, C., Bifulco, G., Arienzo, M.P. and Nappi, C. (1999) Effects of postmenopausal hypoestrogenism on skin collagen. Maturitas, 33, 239-247. http://dx.doi.org/10.1016/S0378-5122(99)00077-8

[6] Söderberg, M.W., Byström, B., Kalamajski, S., Malmström, A. and Ekman-Ordeberg, G. (2009) Gene expressions of small leucine-rich repeat proteoglycans and fibulin-5 are decreased in pelvic organ prolapse. Molecular Human Reproduction, 15, 251-257. http://dx.doi.org/10.1093/molehr/gap011

[7] Stevenson, S. and Thornton, J. (2007) Effect of estrogens on skin aging and the potential role of SERMs. Clinical Interventions in Aging, 2, 283-297.

[8] Lodén, M. (2012) Effect of moisturisers on epidermal barrier function. Clinics in Dermatology, 30, 286-296. http://dx.doi.org/10.1016/j.clindermatol.2011.08.015

[9] Holden, C., English, J., Hoare, C., Jordan, A., Kownacki, S., Turnbull, R. and Staughton, R.C. (2002) Advised best practice for the use of emollients in eczema and other dry skin conditions. Journal of Dermatological Treatment, 13, 103-106. http://dx.doi.org/10.1080/09546630260199442

[10] Pedersen, L. and Jemec, G.B.E. (2006) Mechanical properties and barrier function of healthy human skin. Acta Dermato Venereologica, 86, 308-311. http://dx.doi.org/10.2340/00015555-0080

[11] Jemec, G.B.E. and Wulf, H.C. (1999) Correlation between the greasiness and the plasticizing effect of moisturizers. Acta Dermato Venereologica, 79, 115-117. http://dx.doi.org/10.1080/000155599750011318

[12] Flynn, T.C., Petros, J., Clark, R.E. and Viehman, G.E. (2001) Dry skin and moisturisers. Clinics in Dermatology, 19, 387-392. http://dx.doi.org/10.1016/S0738-081X(01)00199-7

[13] Kerscher, M. and Buntrock, H. (2011) [Anti-aging creams. What really helps?]. Hautarzt, 62, 607-613. 
http://dx.doi.org/10.1007/s00105-011-2137-6

[14] Lupo, M.P. and Cole, A.L. (2007) Cosmeceutical peptides. Dermatology and Therapy, 20, 343-349. http://dx.doi.org/10.1111/j.1529-8019.2007.00148.x

[15] Brown, T.J., Alcorn, D. and Fraser, J.R. (1999) Absorption of hyaluronan applied to the surface of intact skin. Journal of Investigative Dermatology, 113, 740-746. http://dx.doi.org/10.1046/j.1523-1747.1999.00745.x

[16] Kligman, L.H., Do, C.H. and Kligman, A.M. (1984) Topical retinoic acid enhances the repair of ultra violet damaged dermal connective tissue. Connective Tissue Research, 12, 139-150. http://dx.doi.org/10.3109/03008208408992779

[17] Duell, E.A., Derguini, F., Kang, S., Elder, J.T. and Voorhees, J.J. (1996) Extraction of human epidermis treated with retinol yields retro-retinoids in addition to free retinol and retinyl esters. Journal of Investigative Dermatology, 107, 178-182.

http://dx.doi.org/10.1111/1523-1747.ep12329576

[18] Pelle, E., Muizzuddin, N., Mammone, T., Marenus, K. and Maes, D. (1999) Protection against endogenous and UVB-induced oxidative damage in stratum corneum lipids by an antioxidant-containing cosmetic formulation. Photodermatology, Photoimmunology \& Photomedicine, 15, 115-119.

http://dx.doi.org/10.1111/j.1600-0781.1999.tb00070.x

[19] Darr, D., Dunston, S., Faust, H. and Pinnell, S. (1996) Effectiveness of antioxidants (vitamin C and E) with and without sunscreen as topical photoprotectants. Acta Dermato Venereologica, 76, 264-268.

[20] Burton, G.W., Joyce, A. and Ingold, K.U. (1983) Is vitamin $\mathrm{E}$ the only lipid-soluble, chain breaking antioxidant in human blood plasma and erythrocyte membranes? Archives of Biochemistry and Biophysics, 221, 281-290. http://dx.doi.org/10.1016/0003-9861(83)90145-5

[21] Draelos, Z.D. (2007) The latest cosmeceutical approaches for anti-aging. Journal of Cosmetic Dermatology, 6, 2-6. http://dx.doi.org/10.1111/j.1473-2165.2007.00313.x

[22] Bissett, D.L., Miyamoto, K., Sun, P., Li, J. and Berge, C.A. (2004) Topical niacinamide reduces yellowing, wrinkling, red blotchiness, and hyperpigmented spots in aging facial skin. International Journal of Cosmetic Science, 26, 231-238.

http://dx.doi.org/10.1111/j.1467-2494.2004.00228.x

[23] Fitzpatrick, R.E. and Rostan, E.F. (2002) Double-blind, half-face study comparing topical vitamin $C$ and vehicle for rejuvenation of photodamage. Dermatologic Surgery, 28, 231-236. http://dx.doi.org/10.1046/j.1524-4725.2002.01129.x

[24] Nusgens, B.V., Humbert, P., Rougier, A., Colige, A.C., Haftek, M., Lambert, C.A., Richard, A., Creidi, P. and Lapière, C.M. (2001) Topically applied vitamin C enhances the mRNA level of collagens I and III, their processing enzymes and tissue inhibitor of matrix metalloproteinase 1 in the human dermis. Journal of Investigative Dermatology, 116, 853-859. http://dx.doi.org/10.1046/j.0022-202x.2001.01362.x

[25] Haftek, M., Mac-Mary, S., Le Bitoux, M.A., Creidi, P., Seité, S., Rougier, A. and Humbert, P. (2008) Clinical, biometric and structural evaluation of the long-term effects of a topical treatment with ascorbic acid and madecassoside in photoaged human skin. Experimental Dermatology, 17, 946-952.

http://dx.doi.org/10.1111/j.1600-0625.2008.00732.x

[26] Zhai, H., Behnam, S., Villarama, C.D., Arens-Corell, M., Choi, M.J. and Maibach, H.I. (2005) Evaluation of the antioxidant capacity and preventive effects of a topical emulsion and its vehicle control on the skin response to UV exposure. Skin Pharmacology and Physiology, 18, 288-293. http://dx.doi.org/10.1159/000088014

[27] Varani, J., Warner, R.L., Gharaee-Kermani, M., Phan, S.H., Kang, S., Chung, J.H., Wang, Z.Q., Datta, S.C., Fisher, G.J. and Voorhees, J.J. (2000) Vitamin A antagonizes decreased cell growth and elevated collagen-degrading matrix metalloproteinases and stimulates collagen accumulation in naturally aged human skin. Journal of Investigative Dermatology, 114, 480-486. http://dx.doi.org/10.1046/j.1523-1747.2000.00902.x

[28] http://www.courage-khazaka.de

[29] Elsner, P., Wilhelm, D. and Maibach, H.I. (1990) Mechanical properties of human forearm and vulvar skin. British Journal of Dermatology, 122, 607-614. http://dx.doi.org/10.1111/j.1365-2133.1990.tb07282.x

[30] Pierard, G.E. (1989) A critical approach to in vivo mechanical testing of the skin. In: Leveque, J.L., Ed., Cutaneous Investigation in Health and Disease, Marcel Dekker, New York, 215-240.

[31] Cua, A.B., Wilhelm, K.P. and Maibach, H.I. (1990) Elastic properties of human skin: relation to age, sex and anatomical region. Archives of Dermatological Research, 282, 283-288. http://dx.doi.org/10.1007/BF00375720

[32] Barel, A.O., Courage, W. and Clarys, P. (1995) Suction method for measurement of skin mechanical properties: The Cutometer. In: Serup, J. and Jemec, G.B.E. Eds., Handbook of Noninvasive Methods and the Skin, CRC Press, Boca Raton, 335-340.

[33] Enomoto, D.N., Mekkes, J.R., Bossuyt, P.M., Hoekzema, R. and Bos, J.D. (1996) Quantification of cutaneous sclerosis with a skin elasticity meter in patients with generalized scleroderma. Journal of the American Academy of Dermatology, 35, 381-387. http://dx.doi.org/10.1016/S0190-9622(96)90601-5

[34] Rennekampff, H.O., Rabbels, J., Pfau, M. and Schaller, H.E. (2002) [Evaluating scar development with objective computer assisted viscoelastic measurement]. Kongressband/Deutsche Gesellschaft for Chirurgie Kongress, 119, 749-755.

[35] Dobrev, H. (2005) Application of Cutometer area parameters for the study of human skin fatigue. Skin Research and Technology, 11, 120-122. http://dx.doi.org/10.1111/j.1600-0846.2005.00090.x

[36] Rodrigues, L., EEMCO Group (2001) EEMCO guidance to the in vivo assessment of tensile functional properties of the skin. Part 2: Instrumentation and test modes. Skin Pharmacology and Applied Skin Physiology, 14, 52-67. http://dx.doi.org/10.1159/000056334

[37] Heinrich, U., Koop, U., Leneveu-Duchemin, M.C., Osterrieder, K., Bielfeldt, S., Chkarnat, C., Degwert, J., 
Häntschel, D., Jaspers, S., Nissen, H.P., Rohr, M., Schneider, G. and Tronnier, H. (2003) Multicentre comparison of skin hydration in terms of physical, physiological, and product-dependent parameters by the capacitative method (Corenometer CM 825). International Journal of Cosmetic Science, 25, 45-53. http://dx.doi.org/10.1046/j.1467-2494.2003.00172.x

[38] Fluhr, J.W., Kuss, O., Diepgen, T., Lazzerini, S., Pelosi, A., Gloor, M. and Berardesca, E. (2001) Testing for irritation with multifactorial approach: Comparison of eight non-invasive measuring techniques on five different irritation types. British Journal of Dermatology, 145, 696703. http://dx.doi.org/10.1046/j.1365-2133.2001.04431.x

[39] Annen, M. and Yamamoto, K. (1998) Clinical case reports of bioceramides LS lotion: Efficacy in pediatric patients with atopic dermatitis. Journal of Pediatric Dermatology, 17, 45-50.

[40] O’goshi, K. and Serup, J. (2005) Inter-instrumental variation of skin capacitance measured with the Corneometer. Skin Research and Technology, 11, 107-109. http://dx.doi.org/10.1111/j.1600-0846.2005.00086.x

[41] Clarys, P., Barel, A.O. and Gabard, B. (1999) Non-invasive electrical measurements for the evaluation of the hydration state of the skin: comparison between three conventional instruments-The Comeometer ${ }^{\circledR}$, the Ski$\operatorname{con}^{\circledR}$ and the Nova DPM ${ }^{\circledR}$. Skin Research and Technology, 5, 14-20.

http://dx.doi.org/10.1111/j.1600-0846.1999.tb00198.x

[42] Bettinger, J., Gloor, M., Vollert, A., Kleesz, P., Fluhr, J. and Gehring, W. (1999) Comparison of different non-invasive test methods with respect to the effect of different moisturizers on skin. Skin Research and Technology, 5,
21-27.

http://dx.doi.org/10.1111/j.1600-0846.1999.tb00199.x

[43] Edelberg, R. (1977) Relation of electrical properties of skin to structure and physiologic state. Journal of Investigative Dermatology, 69, 324-327. http://dx.doi.org/10.1111/1523-1747.ep12507771

[44] Li, F., Conroy, E., Visscher, M. and Wickett, R.R. (2001) The ability of electrical measurements to predict skin moisturization. II. Correlation between one-hour measurements and long-term results. Journal of Cosmetic Science, 52, 23-33.

[45] Fujioka, N., Hibino, S., Wakahara, A., Kawagishi, T., Taku, K., Mizuno, S., Watanabe, S., Takahashi, H., Hamada, U., Takahashi, Y. and Yonei, Y. (2009) Effects of various soap elements on skin. Anti-Aging Medicine, 6, 109-118. http://dx.doi.org/10.3793/jaam.6.109

[46] Hori, M., Kishimoto, S., Tezuka, Y., Nishigori, H., Nomoto, K., Hamada, U. and Yonei, Y. (2010) Double-blind study on effects of glucosyl ceramide in beet extract on skin elasticity and fibronectin production in human dermal finbrobalsts. Anti-Aging Medicine, 7, 129-142. http://dx.doi.org/10.3793/jaam.7.129

[47] Nguyen, D.Q.A., Potokar, T.S. and Price, P. (2010) An objective long-term evaluation of Integra (a dermal skin substitute) and split thickness skin grafts, in acute burns and reconstructive surgery. Burns, 36, 23-28. http://dx.doi.org/10.1016/j.burns.2009.07.011

[48] Wanitphakdeedecha, R., Eimpunth, S. and Manuskiatti, W. (2011) The effects of mucopolysaccharide polysulphate on hydration and elasticity of human skin. Dermatology Research and Practice, Article ID: 807906. 